\title{
Review \\ Hepatocellular Carcinoma Immunotherapy and the Potential Influence of Gut Microbiome
}

\author{
Sally Temraz ${ }^{1, *}$, Farah Nassar ${ }^{1}$, Firas Kreidieh ${ }^{1}$, Deborah Mukherji ${ }^{1}\left(\mathbb{D}\right.$, Ali Shamseddine ${ }^{1}\left(\mathbb{C}\right.$ and Rihab Nasr ${ }^{2, *} \mathbb{C}$ \\ 1 Department of Internal Medicine, Hematology/Oncology Division, \\ American University of Beirut Medical Center, Riad El Solh, Beirut 1107 2020, Lebanon; \\ fn16@aub.edu.lb (F.N.); fk30@aub.edu.lb (F.K.); dm25@aub.edu.lb (D.M.); as04@aub.edu.lb (A.S.) \\ 2 Department of Anatomy, Cell Biology and Physiology, American University of Beirut Medical Center, \\ Riad El Solh, Beirut 1107 2020, Lebanon \\ * Correspondence: st29@aub.edu.lb (S.T.); rn03@aub.edu.lb (R.N.)
}

Citation: Temraz, S.; Nassar, F.;

Kreidieh, F.; Mukherji, D.;

Shamseddine, A.; Nasr, R.

Hepatocellular Carcinoma

Immunotherapy and the Potential Influence of Gut Microbiome. Int. J. Mol. Sci. 2021, 22, 7800.

https://doi.org/10.3390/ijms22157800

Academic Editors: Silvia Turroni and Riccardo Masetti

Received: 6 June 2021

Accepted: 30 June 2021

Published: 21 July 2021

Publisher's Note: MDPI stays neutral with regard to jurisdictional claims in published maps and institutional affiliations.

Copyright: (c) 2021 by the authors. Licensee MDPI, Basel, Switzerland. This article is an open access article distributed under the terms and conditions of the Creative Commons Attribution (CC BY) license (https:// creativecommons.org/licenses/by/ $4.0 /)$.

\begin{abstract}
Disruptions in the human gut microbiome have been associated with a cycle of hepatocyte injury and regeneration characteristic of chronic liver disease. Evidence suggests that the gut microbiota can promote the development of hepatocellular carcinoma through the persistence of this inflammation by inducing genetic and epigenetic changes leading to cancer. As the gut microbiome is known for its effect on host metabolism and immune response, it comes as no surprise that the gut microbiome may have a role in the response to therapeutic strategies such as immunotherapy and chemotherapy for liver cancer. Gut microbiota may influence the efficacy of immunotherapy by regulating the responses to immune checkpoint inhibitors in patients with hepatocellular carcinoma. Here, we review the mechanisms by which gut microbiota influences hepatic carcinogenesis, the immune checkpoint inhibitors currently being used to treat hepatocellular carcinoma, as well as summarize the current findings to support the potential critical role of gut microbiome in hepatocellular carcinoma (HCC) immunotherapy.
\end{abstract}

Keywords: hepatocellular carcinoma; gut microbiome; microbiota; immunotherapy

\section{Introduction}

Primary liver cancer comprises mainly hepatocellular carcinoma (HCC) in 75-85\% of cases, followed by intrahepatic cholangiocarcinoma in 10-15\%, in addition to other non-common types. In 2018, liver cancer accounted for 841,080 new cases and 781,631 new deaths worldwide, thereby rendering it the sixth most common cancer and the fourth most common cause of cancer-related death in the world; Ferlay, et al. [1]. Liver cancer is characterized by a poor prognosis with a 5-year survival of $18 \%$ unless discovered at an early stage where invasive treatment is the only resolution and includes ablation, surgical resection, or liver transplant. The majority of patients have advanced disease at diagnosis and, until recently, sorafenib was the only treatment option of systemic therapy for those patients. Currently, the standard of care in patients with advanced HCC involves immunotherapy combination of the checkpoint inhibitor atezolizumab and the targeted antibody bevacizumab.

The gut microbiota, also known as the 'forgotten organ', is the largest micro-ecosystem in the human body, which encompasses more than 1014 microorganisms. It is vital to the host's metabolism and immune response, including antitumor response following immunotherapy and chemotherapy [2]. Although the liver is not in direct contact with the microbiota, it has a tight bidirectional link to the gut through the biliary tract, hepatic portal vein, and bile secretions [3,4]. However, dysbiosis, which is defined as qualitative and quantitative alterations of the gut microbiota, has the potential to destroy the gut barrier and increase intestinal penetrability. Moreover, the translocation of gut bacteria, bacterial overgrowth, and dysplasia of the immune system result in a condition known as "leaky 
gut" [5]. Both dysbiosis and the leaky gut are associated with a cycle of hepatocyte injury and regeneration characteristic of chronic liver disease, thereby encouraging the stepwise progression from fibrosis to cirrhosis and ultimately HCC.

In this review, we delve into the mechanism through which the gut microbiota impacts the pathogenesis of various liver diseases leading to HCC and summarize the current findings to support the potential critical role of gut microbiome in HCC immunotherapy.

\section{Role of Gut Microbiota}

The liver is supplied with blood from two sources: the hepatic artery, which originates from the celiac trunk, and the portal vein, which brings blood from the intestines and spleen. Blood carried through the portal vein is rich in nutrients and bacterial components like bacterial DNA, lipopolysaccharides (LPS), and peptidoglycan [6]. Kupffer cells, which are macrophages located in the sinusoids of the liver, eliminate these bacterial components under normal physiological conditions and prevent their harm to the body [7]. The gut microbiota also plays an important role in protecting the portal vein from invasion by pathogens through bacteriocins released by symbiotic bacteria that occupy the intestinal epithelium [8]. The gut microbiota also participates in gut immune maturation, such as the maturation of intestinal $\mathrm{CD}^{+}$and $\mathrm{CD}^{+} \mathrm{T}$ cells and dendritic cells [9].

Moreover, some metabolites that are produced by the gut microbiota regulate the physiological functions of the liver. The gut microbiota ferments dietary fibers to produce short-chain fatty acids, including butyric and propionic acid, which regulate proliferation and differentiation of liver cells and suppress inflammation in the liver by inducing regulatory $\mathrm{T}$ cells through an epigenetic mechanism [10]. The gut microbiota also breakdowns inulin, cellulose, and starch, which are termed indigestible carbohydrates, the end result of which is used by the hepatic cell for growth [11]. Another microbial metabolite resulting from polyphenolics, which are found in berries and pomegranates, is urolithin. This metabolite thwarts harmful substances from entering the portal vein [12]. Thus, gut homeostasis is essential for health.

\section{Mechanisms by Which Gut Microbiota Induce HCC}

There is a close link between dysbiosis and leaky gut; dysbiosis causes the intestinal barrier to be more permeable, whereas the leaky gut allows bacterial metabolites and microbiota-associated molecular patterns (MAMPs) to translocate and reach the liver.

Dysbiosis impacts metabolic pathways in the gut microbiota through production of bacterial metabolites such as bile acids. Gram-positive bacteria have an enhanced capacity for the conversion of bile acid to secondary bile acids [13]. Bacterially generated secondary bile acid deoxycholic acid (DCA) regulates liver sinusoidal cells (LSEC)- and CXCL16-dependent natural killer T cell (NKT) recruitment [14]. DCA was also found to increase levels of toll-like receptor 2 (TLR2) expression on hepatic stellate cells (HSCs), which in turn also increase TLR2 agonist lipoteichoic acid (LTA) in tumor promoting senescence-associated secretory phenotype (SASP) [15]. Moreover, DCA activates the mammalian target of rapamycin (mTOR) pathway in hepatocytes, ultimately resulting in HCC development [16]. In dysbiosis, short chain fatty acids specifically butyrate resulting from digestion of inulin have been found to promote HCC development [17].

MAMPs include LPS, which is a cell wall component of gram-negative bacteria that triggers inflammation via TLR 4 . TLR4 has been shown to mediate hepatic carcinogenesis via resident liver cells such as HSCs, macrophages, or hepatocytes. In addition to contributing to a chronic inflammatory state, TLR4 promotes the development of liver fibrosis and upregulates the expression of epiregulin, a potent HCC-promoting hepatomitogen, in HSCs [18]. Another MAMP is LTA and its receptor is TLR2. TLR2 is essential for the innate immune response to Gram-positive bacteria, being activated by bacterial lipoproteins and peptidoglycan. Once activated, TLR2 leads to a SASP, which seemed to be mediated in collaboration with DCA as well as Cox2 and prostaglandin E in HSCs [15]. In summary, 
the chronically injured liver is subject to increased exposure to a wide range of TLR ligands as well as other bacterial products and metabolites (Figure 1).

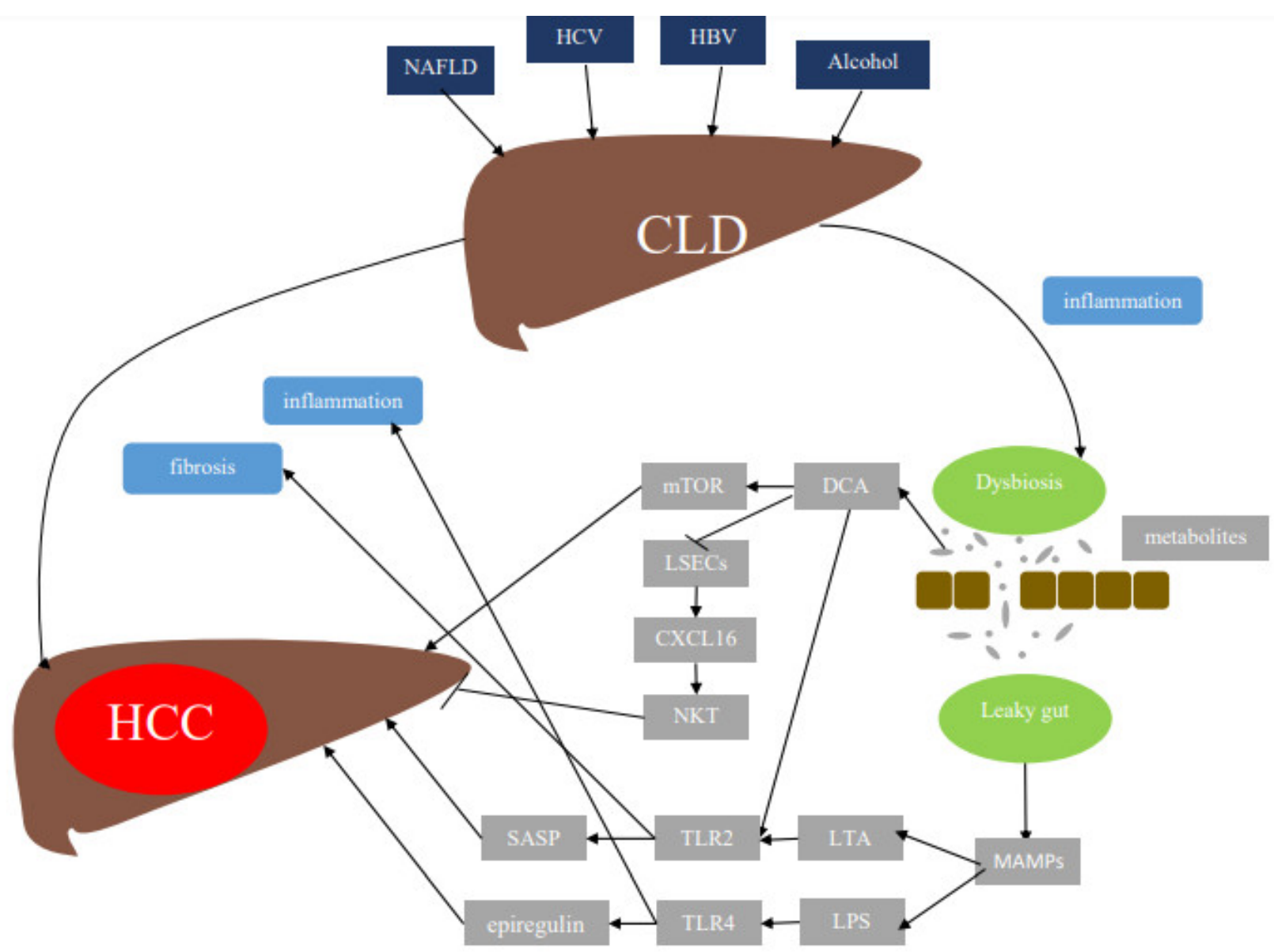

Figure 1. Mechanisms by which the gut microbiome plays a role in hepatocellular carcinoma. Besides the known risk factors for HCC, which include NAFLD, HBV, HCV, and alcohol, dysbiosis and leaky gut resulting from dysfunctional microbiota represent two other major factors leading to hepatic carcinogenesis. As such, several pathways are initiated, leading to HCC, which are detailed above. HCC: hepatocellular carcinoma; CLD: chronic liver disease; NAFLD: non-alcoholic fatty liver disease; HCV: hepatitis C virus; HBV: hepatitis B virus; MAMPs: microbiota-associated molecular patterns; TLR: toll-like receptor; LPS: lipopolysaccharide; LTA: lipoteichoic acid; SASP: senescence-associated secretory phenotype; DCA: deoxycholic acid; NKT: natural killer T cell; LSECs: liver sinusoidal cells; mTOR: mammalian target of rapamycin; CXCL-16: CXC motif ligand 16.

\section{Changes in Gut Microbiota Associated with Different Liver Diseases}

As the gut microbiome plays a critical role as an intermediary in the gut-liver axis, its composition and function evolve as changes in its host take place [19]. For instance, under normal physiological conditions, the majority of gut microbiota consists of microorganisms from Firmicutes phylum as well as from the Actinobacteria and Verrucomicrobia phyla [20]. Their role is to protect the host from overgrowth of pathogenic organisms. However, with different underlying chronic liver diseases (CLDs) come distinct changes in the gut microbiome profile, characterized mainly by loss of microbial diversity. The specific etiologies underlying CLD states have been characterized by unique microbial pathogens and loss of beneficial microorganisms, which are explicitly shown in Table 1. 
Table 1. Human studies involving gut microbial composition in various CLD states.

\begin{tabular}{|c|c|c|}
\hline CLD Type & Microorganism & Reference \\
\hline NAFLD & $\begin{array}{c}\downarrow \text { Prevotella } \\
\uparrow \text { Proteobacteria } \\
\uparrow \text { Fusobacteria } \\
\uparrow \text { Erysipelotrichaceae } \\
\uparrow \text { Enterobacteriaceae } \\
\uparrow \text { Lachnospiraceae } \\
\uparrow \text { Escherichia Shigella } \\
\uparrow \text { Streptococcaceae } \\
\downarrow \text { Firmicutes } \\
\uparrow \text { Bacteroidetes } \\
\downarrow \text { Prevotella } \\
\uparrow \text { Bacteroides } \\
\uparrow \text { Ruminococcus } \\
\uparrow \text { Escherichia coli } \\
\uparrow \text { Bacteroides vulgatus }\end{array}$ & $\begin{array}{l}{[22]} \\
{[23]} \\
{[24]}\end{array}$ \\
\hline Cirrhosis & $\begin{array}{c}\uparrow \text { Enterobacteriaceae } \\
\uparrow \text { Enterococcus } \\
\downarrow \text { Bacteroidetes } \\
\uparrow \text { Proteobacteria } \\
\uparrow \text { Fusobacteria } \\
\uparrow \text { Enterobacteriaceae } \\
\uparrow \text { Streptococcaceae } \\
\uparrow \text { Veillonellaceae } \\
\downarrow \text { Bacteroides } \\
\uparrow \text { Prevotella } \\
\uparrow \text { Clostridium } \\
\uparrow \text { Streptococcus } \\
\uparrow \text { Veillonella } \\
\downarrow \text { Akkermansia } \\
\uparrow \text { Enterobacteriaceae } \\
\uparrow \text { Streptococcaceae }\end{array}$ & [28] \\
\hline $\mathrm{HBV}$ & $\begin{array}{c}\downarrow \text { Bifidobacterium } \\
\downarrow \text { Clostridiaceae } \\
\downarrow \text { Clostridia } \\
\downarrow \text { Ruminococcus } \\
\uparrow \text { Klebsiella } \\
\uparrow \text { Escherichia coli } \\
\uparrow \text { Proteus } \\
\uparrow \text { Enterobacter } \\
\downarrow \text { Bacteroidetes } \\
\uparrow \text { Proteobacteria }\end{array}$ & [30] \\
\hline Cirrhosis + HCC & $\begin{array}{c}\downarrow \text { Bifidobacterium } \\
\uparrow \text { Bacteroidetes } \\
\uparrow \text { Ruminococcaceae }\end{array}$ & [28] \\
\hline $\mathrm{HBV}+\mathrm{HCC}$ & $\begin{array}{c}\downarrow \text { Verrucomicrobia } \\
\uparrow \text { Actinobacteria } \\
\downarrow \text { Faecalibacterium } \\
\downarrow \text { Ruminococcus } \\
\downarrow \text { Ruminoclostridium } \\
\uparrow \text { Escherichia-Shigella } \\
\uparrow \text { Enterococcus }\end{array}$ & [31] \\
\hline
\end{tabular}
hepatocellular carcinoma.

Studies of the human gut microbiome and its association with CLDs have shown some heterogeneous results in terms of the type of abundant microorganisms constituting the gut microbiome of the same liver disease and in terms of abundance of specific bacteria 
(Table 1). For instance, Bifidobacterium, the gram-positive and non-spore forming bacilli, was decreased only in HBV patients and in patients with cirrhosis causing HCC. This bacterium belongs to the Actinobacterium phylum, which has beneficial effects on human health by acting as probiotic, thereby reducing plasma and intestinal endotoxin levels, changing gut microbiota contents, enhancing the gut-liver axis, and modulating the immunity $[3,33]$. On the other hand, the butyrate producing bacteria family Ruminococcus was less abundant in patients with HBV and HCC, but more abundant in patients with NAFLD and cirrhosis plus HCC. Another butyrate-producing bacteria family Clostridia was less abundant in patients with HBV, but more abundant in patients with cirrhosis. Butyrate, a kind of short chain fatty acid, is the major energy source of the intestinal mucosa and plays an important role in immunomodulation [34,35]. The phylum Bacteriodetes is composed of three large classes of gram-negative bacteria. Lower classifications of Bacteroidetes include Prevotella, Bacteriodales, Flavobactericeae, and so on. Bacteriodetes are abundant in patients with NAFLD and cirrhosis plus HCC, but decreased in patients with cirrhosis and HBV. Potentially pathogenic gram-negative bacteria family belonging to the Proteobacteria phylum such as Enterobacteriaceae comprises Escherichia coli, Shigella, Proteus, Klebsiella, and Enterobacter, which are increased in NAFLD, cirrhosis, HCC, and HBV. Enterobacteriaceae are ethanol-producing bacteria capable of causing liver damage and have been associated with levels of serum interleukin-6 (IL-6), IL-1, and tumor necrosis factor (TNF)- $\alpha$ [36,37]. Firmicutes phylum consists of gram-positive bacteria and includes both beneficial (Clostridia, Clostridiaceae, and Ruminococcus) and pathogenic (Enterococcus and Streptococcus) bacteria. Streptococcus are abundant in patients with cirrhosis and NAFLD, while Enterococcus are abundant in HCC. It is possible that the differences in microbial taxonomy are related to the causality of the disease, the geographical area, the target sequencing regions and depths of $16 \mathrm{~S}$ ribosomal RNA gene, or the database that is selected.

\section{Strategies to Manipulate Gut Microbiome for HCC Treatment/Prevention}

Evidence suggests that the gut microbiota can promote the development of HCC through various mechanisms and may influence the efficacy of chemotherapy by modulating the host response to chemotherapeutic drugs, such as facilitation of drug efficacy, mediation of toxicity and abrogation of anticancer effects [38-40], the efficacy of immunotherapy by regulating the responses to the ICIs of patients with different cancers, and the efficacy of targeted therapy by modulating the metabolism and efficacy of some targeted drugs such as sorafenib and Wnt inhibitors [41-43]. Manipulation of the gut microbiota with probiotics, prebiotics, and FMT might be a novel, safe, and low-cost strategy to treat or prevent HCC.

\subsection{Probiotics}

Probiotics are a general term for active, beneficial microorganisms that colonize the human intestines and reproductive system. Probiotics have the potential to mitigate HCC risk by modulating host gut microbiota to promote growth of beneficial microbes and inhibit the growth of harmful ones [44]. Besides the traditional probiotic genera Bifidobacterium and Lactobacillus, a new group of probiotic bacteria, the so-called 'next generation probiotics', is currently emerging that mainly belong to butyrate-producing members of Clostridium clusters IV and XIVa (e.g., Faecalibacterium prausnitzii) or to the health-promoting mucin degraders Akkermansia muciniphila.

Probiotic bacteria can reduce the risk of HCC pathogenesis through multiple processes. For instance, probiotic bacteria promote the growth of beneficial gut microbes that produce anti-inflammatory metabolites with tumor suppression activity. Prohep, a novel probiotic mixture of L. rhamnosus, E. coli Nissle 1917, and heat inactivated VSL\#3 (1:1:1), has been shown to shift the gut microbial community toward certain beneficial bacteria, including the Prevotella and Oscillibacter, which are known producers of anti-inflammatory metabolites, which subsequently reduced the Th17 polarization and promoted the differentiation of anti-inflammatory Treg/Tr1 cells in the gut [45]. Moreover, supplementation 
with probiotics attenuates HCC pathogenesis by downregulating the expression of TLRinduced inflammation. In Wistar rats with thioacetamide-induced liver cirrhosis, early administration of L. plantarum significantly decreased the expression of TLR4, CXCL9, and PREX-2 together with improvement in liver function [46].

Probiotic bacteria also have the ability to promote the epigenetic modulation of host gene expression to mitigate the pathogenesis of HCC. The probiotic bacteria L. acidophilus and B. bifidum reduced the expression of oncomirs (miR-155 and miR-221) and the oncogenes BCL2-like 2 (Bcl-w) and Kristen rat sarcoma viral oncogene homolog (KRAS) in the liver of mice treated with the colon carcinogen azoxymethane. Moreover, mice supplemented with these probiotics had an overexpression of the tumor suppressor miR-122 and tumor suppressor gene transcription factor PU.1 [47]. L. paraplantarum probiotic bacteria can reduce the diabetes-induced DNA damage in the livers of albino Wistar rats [48]. A novel probiotic mixture of S. cerevisiae and L. acidophilus enriched with selenium and glutathione synergistically prevented carbon tetrachloride (CCl4)-induced liver fibrosis by the activation of silent information regulator 1 (SIRT1) in hepatocytes. SIRT1 is a member of class III group of HDAC. Activation of SIRT1 can ameliorate the hepatic oxidative stress, ER stress, and inflammation induced by $\mathrm{CCl} 4$ in the rat livers, as indicated by reduced serum ALT and AST activities [49].

The antiviral activity of probiotics can be beneficial to mitigate HCC risk by preventing chronic HBV and HCV infections. Treatment HepG2 cells with extract of B. adolescentis resulted in a reduction of HBV viral load and cellular degeneration [50]. In HCV subjects, E. faecalis reduced the serum levels of liver damage markers ALT and AST, but failed to reduce $\mathrm{HCV}$ viral load [51]. Administration of probiotic bacteria increased the response rate to pegylated IFN- $\alpha$ and ribavirin treatment by $25 \%$ [52].

Moreover, probiotics prevent hepatic lipotoxicity by ameliorating obesity. In NAFLD patients, supplementation with the probiotic bacteria L. acidophilus and B. lactis can ameliorate liver damage, as indicated by reduced serum levels of ALT, AST, and total cholesterol [53]. In obese NAFLD patients, probiotic administration significantly reduced body weight and total body fat content. Moreover, probiotic administration decreased hepatic inflammation by downregulating the pro-inflammatory cytokine TNF- $\alpha[54,55]$.

Another method by which probiotics mitigate HCC pathogenesis is by controlling aflatoxin contamination. Supplementation with the yogurt containing the probiotic bacteria S. thermophilus, L. rhamnosus, and W. cibaria significantly reduced the urine availability of aflatoxin metabolites [56]. Finally, probiotic bacteria can biotransform non-nutritional dietary components such as proanthocyanidin into simpler metabolites with anticancer effects against HCC. For instance, biotransformed proanthocyanidins inhibit the proliferation of HepG2 cells by depleting mitochondria. The effective concentration of biotransformed proanthocyanidins is significantly low compared with the non-biotransformed material [57].

Overall, probiotics represent a new potential therapeutic strategy for HCC. Probiotic strains not only are a safe and less expensive therapeutic approach, but also can be tailored to different ages. Many more studies are required to clarify how to choose the specific probiotics for different sexes, ages, and diets.

\subsection{Fecal Microbial Transplantation (FMT)}

FMT is a new technique that transplants the functional flora from healthy human feces into the gastrointestinal tract of patients in order to reconstitute new beneficial intestinal flora [58]. FMT may repress the development of HCC by modulating the gut microbiome, reducing the production of some cytotoxic metabolites or inflammatory mediators and reversing the dysbiosis of the gut flora [59]. FMT is an effective treatment against recurrent Clostridium difficile infection. Moreover, it was shown to be a promising therapy for the management of several non-communicable disorders, including inflammatory bowel diseases and metabolic disorders [60]. FMT has increased in popularity because of its efficacy and ease of use and is being evaluated in clinical trials for NASH, NAFD, hepatitis, 
and cirrhosis. However, thus far, there have been few studies on the role of FMT in the treatment of HCC. More animal studies are required to prove the utility and safety of FMT. Possible drawback to its usage may include risk of disease transmission between the donor and recipient, patients' acceptance, undesirable outcomes, and the uncertain impacts on the recipient's immune system [59].

\subsection{Prebiotics}

Prebiotics are a dietary supplement that can selectively stimulate the growth and activity of bacteria and have a beneficial effect on the host [61]. Prebiotics can also restore the stability of the microbial community and reduce proinflammatory pathways that trigger hepatocarcinogenesis [62]. Among the most researched prebiotics, dietary polyphenols are of key importance. They include phenolic acids, flavonoids, and lignins found in nuts, wine, tea, fruits, and vegetables. Polyphenols, among other dietary substances such as coffee, vanadium, dietary fiber, fruits, and vegetables, show encouraging results in terms of chemoprevention in HCC [63]. Tea polyphenols possess potent antioxidant and anti-inflammatory properties and modulate several signaling pathways and provide an effective and promising alternative for the chemoprevention and treatment of HCC [64]. Moreover, curcumin, a major pigment of turmeric, is a natural antioxidant possessing a variety of pharmacological activities and therapeutic properties. Curcumin has shown anti-angiogenic properties in hepatocellular carcinoma cells (HepG2)-implanted nude mice [65] and induces apoptosis through mitochondrial hyperpolarization and mtDNA damage in HepG2 cells [66]. Moreover, curcumin effectively inhibits $N$-diethylnitrosamine (DEN)-induced murine hepatocarcinogenesis [67]. Resveratrol belongs to the stilbene group and is a main component of wine. Resveratrol inhibits urokinase-type plasminogen activator expression and the metastasis of HCC cells and is a powerful chemopreventative agent. The inhibitory effects were associated with the downregulation of the transcription factors of SP-1 signaling pathways [68]. Another prebiotic, the flavonoid quercetin, ameliorates nitric oxide production and nuclear factor NF- $\mathrm{B}$ activation in IL- $1 \beta$-activated rat hepatocytes [69].

\section{Immunotherapy for HCC}

Immune checkpoint blockade has become a turning point in the treatment of HCC, whereby it induces its antitumor effect by modulating the immune system [70]. Immune checkpoint inhibitors (ICIs), including programmed cell death protein-1 (PD-1) antibodies and programmed cell death 1 ligand 1 (PD-L1) antibodies, are potential therapeutic strategies for the treatment of HCC (Table 2).

Nivolumab is an anti-PD-1 antibody that was assessed primarily in the phase I/II nonrandomized CheckMate 040 trial [71]. The trial included a total of 262 patients; 48 patients in a dose-escalation phase and 214 patients in a dose-expansion phase. The overall response rate (ORR) was $20 \%$ and the disease control rate was $64 \%$ with Nivolumab $3 \mathrm{mg} / \mathrm{kg}$ in the dose-expansion phase compared with $15 \%$ and $58 \%$ in patients receiving the doseescalation phase, respectively [71]. Further analysis from this trial revealed a median duration of response of 17 months in sorafenib-naïve patients and 19 months in patients treated previously with sorafenib. Moreover, the 18-month overall survival (OS) rates were $57 \%$ and $44 \%$, respectively [72]. Based on these results, the FDA granted accelerated approval for nivolumab for patients with HCC who progressed on or after sorafenib. The Phase III CheckMate 459 trial compared nivolumab to sorafenib in the first-line treatment of advanced HCC. Median OS was 16.4 months for nivolumab and 14.7 months for sorafenib (HR 0.85 [95\% CI: 0.72-1.02]; $p=0.0752$ ). ORR was $15 \%$ for nivolumab (14 patients with complete response (CR)) and 7\% for sorafenib (5 patients with CR) [73]. 
Table 2. Trials involving immune checkpoint inhibitors for the treatment of HCC.

\begin{tabular}{|c|c|c|c|c|c|c|}
\hline Treatment & Patients & Clinical Phase & $\begin{array}{l}\text { PFS (Months, } \\
95 \% \text { CI) }\end{array}$ & $\begin{array}{l}\text { Median OS } \\
\text { (Months, 95\% } \\
\text { CI) }\end{array}$ & $\operatorname{RR}(\%, 95 \% \mathrm{CI})$ & Reference \\
\hline Nivolumab & Advanced HCC & Phase I/II & $\begin{array}{l}3.4(1.6-6.9), \text { for } \\
\text { DS } 4.1(3.7-5.5) \text {, } \\
\text { for EX }\end{array}$ & $\begin{array}{l}15.0(9.6-20.2), \text { for } \\
\text { DS NR, for EX }\end{array}$ & $\begin{array}{l}15 \%(6-28), \text { for } \\
\text { DS } 20 \%(15-26) \text {, } \\
\text { for EX }\end{array}$ & [71] \\
\hline Nivolumab & & & $3.7(3.1-3.9)$ & $16.4(13.9-18.4)$ & $15 \%$ & \\
\hline Sorafenib & Advanced HCC & Phase III & $3.8(3.7-4.5)$ & $\begin{array}{l}14.7(11.9-17.2) \\
(\text { HR 0.84, } \\
p=0.0419)\end{array}$ & $7 \%$ & [73] \\
\hline $\begin{array}{l}\text { Nivolumab } \\
\text { plus Ipilumab }\end{array}$ & Advanced HCC & Phase I/II & & $\begin{array}{l}22.8(95 \% \mathrm{CI}, \\
9.4 \mathrm{NR})\end{array}$ & $\begin{array}{l}32 \%(95 \% \text { CI, } \\
20-47 \%)\end{array}$ & [79] \\
\hline Pembrolizumab & Advanced HCC & Phase II & $4.8(3.4-6.6)$ & $12.9(9.7-15.5)$ & $17 \%(11-26)$ & [74] \\
\hline Pembrolizumab & \multirow[b]{2}{*}{$\begin{array}{l}\text { Second-line, } \\
\text { Advanced HCC }\end{array}$} & \multirow[b]{2}{*}{ Phase III } & $3.0(2.8-4.1)$ & $13.9(11.6-16.0)$ & $\begin{array}{l}18.3 \\
(14.0-23.4)\end{array}$ & \multirow[b]{2}{*}{ [75] } \\
\hline Placebo & & & $2.8(2.5-4.1)$ & $\begin{array}{l}10.6(8.3-13.5) \\
(\text { HR 0.781, } \\
p=0.023)\end{array}$ & $4.4(1.6-9.4)$ & \\
\hline $\begin{array}{l}\text { Pembrolizumab } \\
\text { plus Lenvatinib }\end{array}$ & $\begin{array}{l}\text { Unresectable } \\
\text { HCC }\end{array}$ & Phase Ib & 9.3 & 22.0 & $46.0 \%(36.0-56.3)$ & [76] \\
\hline $\begin{array}{l}\text { Atezolizumab } \\
\text { plus } \\
\text { bevacizumab }\end{array}$ & $\begin{array}{l}\text { Unresectable } \\
\text { HCC }\end{array}$ & Phase $1 b$ & & & $34 \%$ & [77] \\
\hline $\begin{array}{l}\text { Atezolizumab } \\
\text { plus } \\
\text { Bevacizumab }\end{array}$ & \multirow{2}{*}{$\begin{array}{l}\text { Unresectable } \\
\text { HCC }\end{array}$} & \multirow[b]{2}{*}{ Phase III } & $6.8(5.7-8.3)$ & $\begin{array}{l}67.2 \% \\
(61.3-73.1)\end{array}$ & & \multirow[b]{2}{*}{ [78] } \\
\hline Sorafenib & & & $\begin{array}{l}4.3(4.0-5.6) \\
(\operatorname{HR} 0.59 \\
p<0.001)\end{array}$ & $\begin{array}{l}54.6 \% \\
(45.2-64.0) \\
12 \text { months } \\
\text { response }\end{array}$ & & \\
\hline
\end{tabular}

DS: dose-escalation group; EX: dose-expansion group; NR: not reached; HR: hazard ratio

Pembrolizumab is another anti-PD-1 antibody that was assessed in the non-randomized, open-label phase II KEYNOTE-224 trial. The trial included 104 patients with advanced HCC that were intolerant to sorafenib or have progressed on it. An objective response was seen in 18 (17\%; 95\% CI 11-26) out of 104 patients. The best overall responses were $1(1 \%)$ complete and 17 (16\%) partial responses; meanwhile, 46 (44\%) patients had stable disease, $34(33 \%)$ had progressive disease, and six (6\%) patients were not assessable [74]. Based on these results, the FDA granted accelerated approval for the use of pembrolizumab in patients progressing on sorafenib. Another phase III trial comparing pembrolizumab to placebo in the second-line treatment of advanced HCC did not meet its primary endpoints (OS and PFS) based on the rigorous statistical plan [75]. The combination of lenvantanib, an inhibitor of vascular endothelial growth factor receptor (VEGFR), of fibroblast growth factor receptor, of platelet-derived growth factor receptor (PDGFR), and other growth signaling kinases, and pembrolizumab was assessed in the phase $\mathrm{Ib}$ trial of 104 patients with unresectable HCC [76]. This combination is currently being investigated in a phase III trial against lenvantanib alone as a front-line therapy for unresectable or metastatic HCC (NCT03713593).

Atezolizumab is an anti-PD-L1 antibody that has been assessed mainly in combination with the VEGF inhibitor bevacizumab. This combination showed an ORR of $34 \%$ in patients with metastatic or unresectable HCC in a phase Ib trial [77]. Further analysis from the phase III IMbrave150 trial showed superior results of this combination over sorafenib in the 
first-line treatment of unresectable HCC [78]. However, prior to initiation of this regimen, patients should undergo endoscopic evaluation and management of esophageal varices within 6 months prior to treatment and based on the assessment of bleeding risk.

\section{Influence of Gut Microbiome on Cancer Immunotherapy}

A number of recent studies suggest that manipulating the microbiota may modulate the response to cancer immunotherapy. Oral administration of Bifidobacterium alone improved tumor control to the same degree as PD-L1 specific antibody therapy, and combination treatment nearly abolished tumor outgrowth. Augmented dendritic cell function leading to enhanced $\mathrm{CD} 8^{+} \mathrm{T}$ cell priming and accumulation in the tumor microenvironment mediated the effect in melanoma [80]. Another study examining oral and gut microbiota profiles in melanoma patients receiving PD-1 immunotherapy $(n=112)$ revealed significant differences in the diversity and composition of the patient gut microbiome of responders versus non-responders to immunotherapy. Analysis of 43 patient fecal microbiome samples by $16 S$ ribosomal RNA gene sequencing showed an enrichment of Clostridiales, Ruminococcaceae, and Faecalibacterium in responders to anti-PD-1 treatment and Bacteroidales in non-responders. Twenty-five samples from the same cohort were analyzed by whole genome shotgun sequencing, confirming the enrichment of Feacalibacterium spp. in responders [81]. Analysis of baseline stool samples from metastatic melanoma patients before immunotherapy treatment, through an integration of $16 \mathrm{~S}$ ribosomal RNA gene sequencing, metagenomic shotgun sequencing, and quantitative polymerase chain reaction for selected bacteria, revealed a significant association between commensal microbial composition and clinical response. Bacterial species more abundant in responders included Bifidobacterium longum, Collinsella aerofaciens, Enterococcus faecium, Lactobacillus animalis, Parabacteroides merdae, Roseburia intestinalis, and Veillonella parvula [82]. Moreover, germ-free mice that were colonized with bacteria were shown to be enriched in murine and human responders to ICIs, immune responsiveness was augmented via increased Thelper 1 response, increased frequency of tumor-residing Batf3-lineage dendritic cells, and decreased frequency of colon-derived peripheral regulatory T-cells. Moreover, baseline gut microbiota enriched with Faecalibacterium and other Firmicutes was associated with beneficial clinical response to immune checkpoint inhibitor targeting cytotoxic T-lymphocyte-associated protein 4 (CTLA-4) (Ipilimumab) in melanoma patients [83]. In non-small cell lung cancer and renal cell carcinoma, the commensal that was most significantly associated with a favorable clinical outcome in both cancer types was Akkermansia muciniphila [84]. In pancreatic ductal adenocarcinoma, bacterial ablation was associated with immunogenic reprogramming of the PDA tumor microenvironment, including a reduction in myeloid-derived suppressor cells and an increase in M1 macrophage differentiation, promoting Th1 differentiation of $\mathrm{CD}^{+}{ }^{+} \mathrm{T}$ cells and $\mathrm{CD} 8^{+} \mathrm{T}$ cell activation. Bacterial ablation also enabled efficacy for checkpoint-targeted immunotherapy by upregulating PD-1 expression [85]. These lines of evidence indicated that specific commensal microbes may shape patients' responses to ICI immunotherapy, even though the gut bacteria that were associated with response across these published studies do not overlap.

Chronic antibiotic therapy is known to lead to gut dysbiosis and may disrupt this association, potentially diminishing the benefit of ICIs. Recently, several groups have reported a negative correlation between antibiotic exposure and outcomes for patients receiving treatment with ICIs for advanced solid cancers. In a retrospective study examining the influence of broad spectrum antibiotics on immunotherapy for advanced cancer, the use of antibiotics resulted in shorter progression free survival and OS [86]. The results from phase 1 trials in patients with renal cell carcinoma and non-small cell lung cancer showed that antibiotic use within 30 days of initiating ICI was associated with worse OS [87]. Antibiotic use in advanced non-squamous non-small cell lung cancer patients receiving ICI as second or later lines was identified as the only parameter statistically significantly associated with progression free survival and OS [88]. Moreover, in patients with advanced epithelial tumors, treatment with antibiotics inhibited the clinical benefit from ICIs [84]. Patients treated 
with antibiotics had significantly lower progression-free survival and OS rates compared with patients who had not received antibiotics. FMT from cancer patients who responded to ICIs into germ-free or antibiotic-treated mice ameliorated the antitumor effects of PD-1 blockade, whereas FMT from non-responding patients failed to do so. Metagenomics of patient stool samples at diagnosis revealed correlations between clinical responses to ICIs and the relative abundance of Akkermansia muciniphila. Oral supplementation with $A$. muciniphila after FMT with non-responder feces restored the efficacy of PD-1 blockade in an interleukin-12-dependent manner by increasing the recruitment of CCR9+CXCR3+CD4+ $\mathrm{T}$ lymphocytes into mouse tumor beds [84]. In a phase 1 clinical trial to assess the safety and feasibility of FMT and reinduction of anti-PD-1 immunotherapy in 10 patients with anti-PD-1-refractory metastatic melanoma, clinical responses were seen in three patients. Treatment with FMT was associated with favorable changes in immune cell infiltrates and gene expression profiles in both the gut lamina propria and the tumor microenvironment [89]>. Moreover, gut microbiota may secrete modulators or generate metabolites to improve HCC cells' sensitivity to apoptosis induction and increase the response to ICI in advanced HCC patients [90].

\section{Impact of Gut Microbiome on HCC Immunotherapy and Potential Use of Gut Microbiome Targeting Approaches}

Zheng et al. reported the response to anti-PD-1 antibody immunotherapy in patients with HCC refractory to sorafenib [91]. Responders included those patients with complete response, partial response, or stable disease. Fecal samples were collected at intervals. In this study, non-responders had increased Proteobacteria from the third week, which became dominant by week twelve. However, responders had enriched Akkermansia muciniphila and Ruminococcaceae spp. [91]. These results suggest that the gut microbiome could possibly affect the outcome of anti-PD-1 immunotherapy in HCC patients.

Hepatic cirrhosis is often an underlying condition in HCC patients. Cirrhosis is associated with an extreme dysbiosis, which, in some circumstances, can contribute to drug resistance. It is thus reasonable to speculate that modulating the gut microbiome very likely has an impact on the treatment of HCC. Studies addressing molecular interactions underlying the effects of the microbiota on HCC development and antitumor immune responses are currently being pursued by different groups. For instance, a multicenter, randomized, double-blind, placebo-controlled study of nutritional supplementation with probiotics to prevent the development of HCC in cirrhosis patients (NCT03853928) will start recruiting patients. Another trial (NCT02021253) examined the effect of the administration of probiotics on intestinal barrier function in patients with chronic liver disease (fibrosis stage F3 or F4) operated on for HCC. A clinical trial combining vancomycin treatment with immune checkpoint blockade has recently opened at the National Cancer Institute (NCT03785210). This study will hopefully answer whether combining checkpoint inhibition with selective manipulation of the microbiota will be beneficial in patients with HCC.

\section{Conclusions}

Based on the growing body of evidence, it is becoming clear that modulation of the gut microbiome poses as a potential adjunct to current anti-cancer therapeutic strategies. Given that patients with HCC and other CLDs are subject to dysbiosis, it is enticing to speculate that dysbiosis is at the basis of immunotherapy failure in some patients and modulation of the gut microbiome in a way to overcome the state of dysbiosis may have a strong therapeutic effect in patients with HCC. For now, it is still not definite whether the current findings on the role of the gut microbiome in antitumor immune responses from animal models, as well as from patients with other tumor types, also apply to patients with HCC. New investigations on the gut microbiome, especially those focusing on fecal microbiota transplantation/probiotics, are clearly warranted to assist in the development of new paradigms and personalized treatments to enhance immunotherapy of HCC 
Author Contributions: Conceptualization, S.T. and R.N.; data acquisition, F.K. and F.N.; writingoriginal draft preparation, S.T. and R.N.; writing-review and editing, D.M., A.S., and F.N.; supervision, S.T. All authors have read and agreed to the published version of the manuscript.

Funding: This research received no external funding.

Institutional Review Board Statement: Not applicable.

Informed Consent Statement: Not applicable.

Conflicts of Interest: The authors declare no conflict of interest.

$\begin{array}{ll}\text { Abbreviations } \\ \text { HCC } & \text { Hepatocellular carcinoma } \\ \text { LPS } & \text { Lipopolysaccharides } \\ \text { MAMPs } & \text { Microbiota-associated molecular patterns } \\ \text { DCA } & \text { Deoxycholic acid } \\ \text { LSEC } & \text { Liver sinusoidal cells } \\ \text { NKT } & \text { Natural killer T cell } \\ \text { TLR2 } & \text { Toll-like receptor 2 } \\ \text { HSC } & \text { Hepatic stellate cells } \\ \text { LTA } & \text { Lipoteichoic acid } \\ \text { SASP } & \text { Senescence-associated secretory phenotype } \\ \text { mTOR } & \text { Mammalian target of rapamycin } \\ \text { CLD } & \text { Chronic liver disease } \\ \text { NAFLD } & \text { Non-alcoholic fatty liver disease } \\ \text { HCV } & \text { Hepatitis C virus } \\ \text { HBV } & \text { Hepatitis B virus } \\ \text { IL-6 } & \text { Interleukin-6 (IL-6) } \\ \text { TNF- } \alpha & \text { Tumor necrosis factor- } \alpha \\ \text { ICIs } & \text { Immune checkpoint inhibitors } \\ \text { PD-1 } & \text { Programmed cell death protein-1 } \\ \text { PD-L1 } & \text { Programmed cell death 1 ligand 1 } \\ \text { ORR } & \text { Overall response rate } \\ \text { OS } & \text { Overall survival } \\ \text { CR } & \text { Complete response } \\ \text { VEGFR } & \text { Vascular endothelial growth factor receptor } \\ \text { PDGFR } & \text { Platelet-derived growth factor receptor } \\ \text { CTLA-4 } & \text { Cytotoxic T-lymphocyte-associated protein } 4 \\ \text { FMT } & \text { Fecal microbiota transplantation } \\ \text { SIRT1 } & \text { Silent information regulator 1 } \\ \text { CCL4 } & \text { Carbon tetrachloride } \\ \text { HepG2 } & \text { Hepatocellular carcinoma cells } \\ \text { DEN } & \text { N-diethylnitrosamine } \\ & \\ \text { HCI }\end{array}$

\section{References}

1. Ferlay, J.; Ervik, M.; Lam, F.; Colombet, M.; Mery, L.; Piñeros, M.; Znaor, A.; Soerjomataram, I.; Bray, F. Global Cancer Observatory: Cancer Today; International Agency for Research on Cancer: Lyon, France, 2018.

2. Nicholson, J.K.; Holmes, E.; Kinross, J.; Burcelin, R.; Gibson, G.; Jia, W.; Pettersson, S. Host-gut microbiota metabolic interactions. Science 2012, 336, 1262-1267. [CrossRef] [PubMed]

3. Wan, M.L.; El-Nezami, H. Targeting gut microbiota in hepatocellular carcinoma: Probiotics as a novel therapy. Hepatobiliary Surg. Nutr. 2018, 7, 11. [CrossRef]

4. Stärkel, P.; Schnabl, B. Bidirectional Communication between Liver and Gut during Alcoholic Liver Disease. Semin Liver Dis. 2016, 36, 331-339. [CrossRef] [PubMed]

5. Compare, D.; Coccoli, P.; Rocco, A.; Nardone, O.; De Maria, S.; Cartenì, M.; Nardone, G. Gut-liver axis: The impact of gut microbiota on non alcoholic fatty liver disease. Nutr. Metab. Cardiovasc. Dis. 2012, 22, 471-476. [CrossRef] [PubMed]

6. Brandl, K.; Kumar, V.; Eckmann, L. Gut-liver axis at the frontier of host-microbial interactions. Am. J. Physiol. Gastrointest. Liver Physiol. 2017, 312, G413-G419. [CrossRef]

7. Dixon, L.J.; Barnes, M.; Tang, H.; Pritchard, M.T.; Nagy, L.E. Kupffer cells in the liver. Compr. Physiol. 2013, 3, 785-797. 
8. Trivedi, P.J.; Adams, D.H. Gut-liver immunity. J. Hepatol. 2016, 64, 1187-1189. [CrossRef]

9. Chung, H.; Pamp, S.J.; Hill, J.A.; Surana, N.K.; Edelman, S.M.; Troy, E.B.; Reading, N.C.; Villablanca, E.J.; Wang, S.; Mora, J.R. Gut immune maturation depends on colonization with a host-specific microbiota. Cell 2012, 149, 1578-1593. [CrossRef]

10. Furusawa, Y.; Obata, Y.; Fukuda, S.; Endo, T.A.; Nakato, G.; Takahashi, D.; Nakanishi, Y.; Uetake, C.; Kato, K.; Kato, T. Commensal microbe-derived butyrate induces the differentiation of colonic regulatory T cells. Nature 2013, 504, 446-450. [CrossRef]

11. Weitkunat, K.; Schumann, S.; Petzke, K.J.; Blaut, M.; Loh, G.; Klaus, S. Effects of dietary inulin on bacterial growth, short-chain fatty acid production and hepatic lipid metabolism in gnotobiotic mice. J. Nutr. Biochem. 2015, 26, 929-937. [CrossRef]

12. Singh, R.; Chandrashekharappa, S.; Bodduluri, S.R.; Baby, B.V.; Hegde, B.; Kotla, N.G.; Hiwale, A.A.; Saiyed, T.; Patel, P.; Vijay-Kumar, M. Enhancement of the gut barrier integrity by a microbial metabolite through the Nrf2 pathway. Nat. Commun. 2019, 10, 1-18. [CrossRef]

13. Yoshimoto, S.; Loo, T.M.; Atarashi, K.; Kanda, H.; Sato, S.; Oyadomari, S.; Iwakura, Y.; Oshima, K.; Morita, H.; Hattori, M. Obesity-induced gut microbial metabolite promotes liver cancer through senescence secretome. Nature 2013, 499, 97-101. [CrossRef]

14. Ma, C.; Han, M.; Heinrich, B.; Fu, Q.; Zhang, Q.; Sandhu, M.; Agdashian, D.; Terabe, M.; Berzofsky, J.A.; Fako, V. Gut microbiomemediated bile acid metabolism regulates liver cancer via NKT cells. Science 2018, 360, 6391. [CrossRef] [PubMed]

15. Loo, T.M.; Kamachi, F.; Watanabe, Y.; Yoshimoto, S.; Kanda, H.; Arai, Y.; Nakajima-Takagi, Y.; Iwama, A.; Koga, T.; Sugimoto, Y. Gut microbiota promotes obesity-associated liver cancer through PGE2-mediated suppression of antitumor immunity. Cancer Discov. 2017, 7, 522-538. [CrossRef] [PubMed]

16. Yamada, S.; Takashina, Y.; Watanabe, M.; Nagamine, R.; Saito, Y.; Kamada, N.; Saito, H. Bile acid metabolism regulated by the gut microbiota promotes non-alcoholic steatohepatitis-associated hepatocellular carcinoma in mice. Oncotarget 2018, 9, 9925. [CrossRef] [PubMed]

17. Singh, V.; San Yeoh, B.; Chassaing, B.; Xiao, X.; Saha, P.; Olvera, R.A.; Lapek, J.D., Jr.; Zhang, L.; Wang, W.-B.; Hao, S. Dysregulated microbial fermentation of soluble fiber induces cholestatic liver cancer. Cell 2018, 175, 679-694. e622. [CrossRef]

18. Dapito, D.H.; Mencin, A.; Gwak, G.-Y.; Pradere, J.-P.; Jang, M.-K.; Mederacke, I.; Caviglia, J.M.; Khiabanian, H.; Adeyemi, A.; Bataller, R. Promotion of hepatocellular carcinoma by the intestinal microbiota and TLR4. Cancer Cell 2012, 21, 504-516. [CrossRef] [PubMed]

19. Cho, I.; Blaser, M.J. The human microbiome: At the interface of health and disease. Nat. Rev. Genet. 2012, 13, 260-270. [CrossRef]

20. Acharya, C.; Bajaj, J.S. Altered microbiome in patients with cirrhosis and complications. Clin. Gastroenterol. Hepatol. 2019, 17, 307-321. [CrossRef] [PubMed]

21. Shen, F.; Zheng, R.D.; Sun, X.Q.; Ding, W.J.; Wang, X.Y.; Fan, J.G. Gut microbiota dysbiosis in patients with non-alcoholic fatty liver disease. Hepatobiliary Pancreat Dis. Int. 2017, 16, 375-381. [CrossRef]

22. Wang, B.; Jiang, X.; Cao, M.; Ge, J.; Bao, Q.; Tang, L.; Chen, Y.; Li, L. Altered Fecal Microbiota Correlates with Liver Biochemistry in Nonobese Patients with Non-alcoholic Fatty Liver Disease. Sci. Rep. 2016, 6, 32002. [CrossRef] [PubMed]

23. Boursier, J.; Mueller, O.; Barret, M.; Machado, M.; Fizanne, L.; Araujo-Perez, F.; Guy, C.D.; Seed, P.C.; Rawls, J.F.; David, L.A. The severity of nonalcoholic fatty liver disease is associated with gut dysbiosis and shift in the metabolic function of the gut microbiota. Hepatology 2016, 63, 764-775. [CrossRef] [PubMed]

24. Loomba, R.; Seguritan, V.; Li, W.; Long, T.; Klitgord, N.; Bhatt, A.; Dulai, P.S.; Caussy, C.; Bettencourt, R.; Highlander, S.K. Gut microbiome-based metagenomic signature for non-invasive detection of advanced fibrosis in human nonalcoholic fatty liver disease. Cell Metab. 2017, 25, 1054-1062. e1055. [CrossRef]

25. Liu, J.; Wu, D.; Ahmed, A.; Li, X.; Ma, Y.; Tang, L.; Mo, D.; Ma, Y.; Xin, Y. Comparison of the gut microbe profiles and numbers between patients with liver cirrhosis and healthy individuals. Curr. Microbiol. 2012, 65, 7-13. [CrossRef]

26. Chen, Y.; Yang, F.; Lu, H.; Wang, B.; Chen, Y.; Lei, D.; Wang, Y.; Zhu, B.; Li, L. Characterization of fecal microbial communities in patients with liver cirrhosis. Hepatology 2011, 54, 562-572. [CrossRef] [PubMed]

27. Qin, N.; Yang, F.; Li, A.; Prifti, E.; Chen, Y.; Shao, L.; Guo, J.; Le Chatelier, E.; Yao, J.; Wu, L. Alterations of the human gut microbiome in liver cirrhosis. Nature 2014, 513, 59-64. [CrossRef]

28. Ponziani, F.R.; Bhoori, S.; Castelli, C.; Putignani, L.; Rivoltini, L.; Del Chierico, F.; Sanguinetti, M.; Morelli, D.; Paroni Sterbini, F.; Petito, V. Hepatocellular carcinoma is associated with gut microbiota profile and inflammation in nonalcoholic fatty liver disease. Hepatology 2019, 69, 107-120. [CrossRef]

29. Zeng, Y.; Chen, S.; Fu, Y.; Wu, W.; Chen, T.; Chen, J.; Yang, B.; Ou, Q. Gut microbiota dysbiosis in patients with hepatitis B virus-induced chronic liver disease covering chronic hepatitis, liver cirrhosis and hepatocellular carcinoma. J. Viral Hepat. 2020, 27, 143-155. [CrossRef]

30. Wei, X.; Yan, X.; Zou, D.; Yang, Z.; Wang, X.; Liu, W.; Wang, S.; Li, X.; Han, J.; Huang, L. Abnormal fecal microbiota community and functions in patients with hepatitis B liver cirrhosis as revealed by a metagenomic approach. BMC Gastroenterol. 2013, 13, 1-8. [CrossRef]

31. Ren, Z.; Li, A.; Jiang, J.; Zhou, L.; Yu, Z.; Lu, H.; Xie, H.; Chen, X.; Shao, L.; Zhang, R. Gut microbiome analysis as a tool towards targeted non-invasive biomarkers for early hepatocellular carcinoma. Gut 2019, 68, 1014-1023. [CrossRef]

32. Liu, Q.; Li, F.; Zhuang, Y.; Xu, J.; Wang, J.; Mao, X.; Zhang, Y.; Liu, X. Alteration in gut microbiota associated with hepatitis B and non-hepatitis virus related hepatocellular carcinoma. Gut Pathog. 2019, 11, 1. [CrossRef] 
33. Xu, M.; Wang, B.; Fu, Y.; Chen, Y.; Yang, F.; Lu, H.; Chen, Y.; Xu, J.; Li, L. Changes of fecal Bifidobacterium species in adult patients with hepatitis B virus-induced chronic liver disease. Microb. Ecol. 2012, 63, 304-313. [CrossRef]

34. So, D.; Whelan, K.; Rossi, M.; Morrison, M.; Holtmann, G.; Kelly, J.T.; Shanahan, E.R.; Staudacher, H.M.; Campbell, K.L. Dietary fiber intervention on gut microbiota composition in healthy adults: A systematic review and meta-analysis. Am. J. Clin. Nutr. 2018, 107, 965-983. [CrossRef] [PubMed]

35. Rivière, A.; Selak, M.; Lantin, D.; Leroy, F.; De Vuyst, L. Bifidobacteria and butyrate-producing colon bacteria: Importance and strategies for their stimulation in the human gut. Front. Microbiol. 2016, 7, 979. [CrossRef] [PubMed]

36. Zhu, L.; Baker, S.S.; Gill, C.; Liu, W.; Alkhouri, R.; Baker, R.D.; Gill, S.R. Characterization of gut microbiomes in nonalcoholic steatohepatitis (NASH) patients: A connection between endogenous alcohol and NASH. Hepatology 2013, 57, 601-609. [CrossRef] [PubMed]

37. Tan, C.; Ling, Z.; Huang, Y.; Cao, Y.; Liu, Q.; Cai, T.; Yuan, H.; Liu, C.; Li, Y.; Xu, K. Dysbiosis of intestinal microbiota associated with inflammation involved in the progression of acute pancreatitis. Pancreas 2015, 44, 868-875. [CrossRef] [PubMed]

38. Iida, N.; Dzutsev, A.; Stewart, C.A.; Smith, L.; Bouladoux, N.; Weingarten, R.A.; Molina, D.A.; Salcedo, R.; Back, T.; Cramer, S. Commensal bacteria control cancer response to therapy by modulating the tumor microenvironment. Science 2013, 342, 967-970. [CrossRef]

39. Viaud, S.; Saccheri, F.; Mignot, G.; Yamazaki, T.; Daillère, R.; Hannani, D.; Enot, D.P.; Pfirschke, C.; Engblom, C.; Pittet, M.J. The intestinal microbiota modulates the anticancer immune effects of cyclophosphamide. Science 2013, 342, 971-976. [CrossRef]

40. Alexander, J.L.; Wilson, I.D.; Teare, J.; Marchesi, J.R.; Nicholson, J.K.; Kinross, J.M. Gut microbiota modulation of chemotherapy efficacy and toxicity. Nat. Rev. Gastroenterol. Hepatol. 2017, 14, 356-365. [CrossRef]

41. Ervin, S.M.; Hanley, R.P.; Lim, L.; Walton, W.G.; Pearce, K.H.; Bhatt, A.P.; James, L.I.; Redinbo, M.R. Targeting regorafenib-induced toxicity through inhibition of gut microbial $\beta$-glucuronidases. ACS Chem. Biol. 2019, 14, 2737-2744. [CrossRef]

42. Huang, J.; Kelly, C.P.; Bakirtzi, K.; Gálvez, J.A.V.; Lyras, D.; Mileto, S.J.; Larcombe, S.; Xu, H.; Yang, X.; Shields, K.S. Clostridium difficile toxins induce VEGF-A and vascular permeability to promote disease pathogenesis. Nat. Microbiol. 2019, 4, 269-279. [CrossRef] [PubMed]

43. Suh, S.H.; Choe, K.; Hong, S.P.; Jeong, S.H.; Mäkinen, T.; Kim, K.S.; Alitalo, K.; Surh, C.D.; Koh, G.Y.; Song, J.H. Gut microbiota regulates lacteal integrity by inducing VEGF-C in intestinal villus macrophages. EMBO Rep. 2019, 20, e46927. [CrossRef] [PubMed]

44. De Leblanc, A.D.M.; Matar, C.; Perdigón, G. The application of probiotics in cancer. Br. J. Nutr. 2007, 98, S105-S110. [CrossRef] [PubMed]

45. Li, J.; Sung, C.Y.J.; Lee, N.; Ni, Y.; Pihlajamäki, J.; Panagiotou, G.; El-Nezami, H. Probiotics modulated gut microbiota suppresses hepatocellular carcinoma growth in mice. Proc. Natl. Acad. Sci. USA 2016, 113, E1306-E1315. [CrossRef] [PubMed]

46. Elshaer, A.M.; El-Kharashi, O.A.; Hamam, G.G.; Nabih, E.S.; Magdy, Y.M.; Abd El Samad, A.A. Involvement of TLR4/ CXCL9/ PREX-2 pathway in the development of hepatocellular carcinoma (HCC) and the promising role of early administration of lactobacillus plantarum in Wistar rats. Tissue Cell 2019, 60, 38-47. [CrossRef] [PubMed]

47. Heydari, Z.; Rahaie, M.; Alizadeh, A.M. Different anti-inflammatory effects of Lactobacillus acidophilus and Bifidobactrum bifidioum in hepatocellular carcinoma cancer mouse through impact on microRNAs and their target genes. J. Nutr. Intermed. Metab. 2019, 16, 100096. [CrossRef]

48. Mihailović, M.; Živković, M.; Jovanović, J.A.; Tolinački, M.; Sinadinović, M.; Rajić, J.; Uskoković, A.; Dinić, S.; Grdović, N.; Golić, N.; et al. Oral administration of probiotic Lactobacillus paraplantarum BGCG11 attenuates diabetes-induced liver and kidney damage in rats. J. Funct. Foods 2017, 38, 427-437. [CrossRef]

49. Liu, Y.; Liu, Q.; Hesketh, J.; Huang, D.; Gan, F.; Hao, S.; Tang, S.; Guo, Y.; Huang, K. Protective effects of selenium-glutathioneenriched probiotics on CCl4-induced liver fibrosis. J. Nutr. Biochem. 2018, 58, 138-149. [CrossRef]

50. Lee, D.K.; Kang, J.Y.; Shin, H.S.; Park, I.H.; Ha, N.J. Antiviral activity of Bifidobacterium adolescentis SPM0212 against Hepatitis B virus. Arch. Pharmacal Res. 2013, 36, 1525-1532. [CrossRef]

51. Oo, K.M.; Lwin, A.A.; Kyaw, Y.Y.; Tun, W.M.; Fukada, K.; Goshima, A.; Shimada, T.; Okada, S. Safety and long-term effect of the probiotic FK-23 in patients with hepatitis C virus infection. Biosci. MicrobiotaFood Health 2016, 35, 123-128. [CrossRef]

52. Allam, N.; Salem, M.; Hassan, E.; Nabieh, M. Lactobacillus acidophilus and Bifidobacteria spp having antibacterial and antiviral effects on chronic HCV infection. Afr. J. Microbiol. Res. 2019, 13, 77-90. [CrossRef]

53. Nabavi, S.; Rafraf, M.; Somi, M.H.; Homayouni-Rad, A.; Asghari-Jafarabadi, M. Effects of probiotic yogurt consumption on metabolic factors in individuals with nonalcoholic fatty liver disease. J. Dairy Sci. 2014, 97, 7386-7393. [CrossRef]

54. Ahn, S.B.; Jun, D.W.; Kang, B.-K.; Lim, J.H.; Lim, S.; Chung, M.-J. Randomized, Double-blind, Placebo-controlled Study of a Multispecies Probiotic Mixture in Nonalcoholic Fatty Liver Disease. Sci. Rep. 2019, 9, 5688. [CrossRef] [PubMed]

55. Duseja, A.; Acharya, S.K.; Mehta, M.; Chhabra, S.; Rana, S.; Das, A.; Dattagupta, S.; Dhiman, R.K.; Chawla, Y.K. High potency multistrain probiotic improves liver histology in non-alcoholic fatty liver disease (NAFLD): A randomised, double-blind, proof of concept study. BMJ Open Gastroenterol. 2019, 6, e000315. [CrossRef] [PubMed]

56. Nduti, N.; McMillan, A.; Seney, S.; Sumarah, M.; Njeru, P.; Mwaniki, M.; Reid, G. Investigating probiotic yoghurt to reduce an aflatoxin B1 biomarker among school children in eastern Kenya: Preliminary study. Int. Dairy J. 2016, 63, 124-129. [CrossRef] 
57. Rupasinghe, H.P.V.; Parmar, I.; Neir, S.V. Biotransformation of Cranberry Proanthocyanidins to Probiotic Metabolites by Lactobacillus rhamnosus Enhances Their Anticancer Activity in HepG2 Cells In Vitro. Oxidative Med. Cell. Longev. 2019, $2019,4750795$. [CrossRef] [PubMed]

58. Wang, J.-W.; Kuo, C.-H.; Kuo, F.-C.; Wang, Y.-K.; Hsu, W.-H.; Yu, F.-J.; Hu, H.-M.; Hsu, P.-I.; Wang, J.-Y.; Wu, D.-C. Fecal microbiota transplantation: Review and update. J. Formos. Med. Assoc. 2019, 118, S23-S31. [CrossRef]

59. Bibbo, S.; Ianiro, G.; Gasbarrini, A.; Cammarota, G. Fecal microbiota transplantation: Past, present and future perspectives. Minerva Gastroenterol. E Dietol. 2017, 63, 420-430.

60. Smits, L.P.; Bouter, K.E.; de Vos, W.M.; Borody, T.J.; Nieuwdorp, M. Therapeutic potential of fecal microbiota transplantation. Gastroenterology 2013, 145, 946-953. [CrossRef]

61. Holscher, H.D. Dietary fiber and prebiotics and the gastrointestinal microbiota. Gut Microbes 2017, 8, 172-184. [CrossRef]

62. Ambalam, P.; Raman, M.; Purama, R.K.; Doble, M. Probiotics, prebiotics and colorectal cancer prevention. Best Pract. Res. Clin. Gastroenterol. 2016, 30, 119-131. [CrossRef] [PubMed]

63. Mandair, D.S.; Rossi, R.E.; Pericleous, M.; Whyand, T.; Caplin, M. The impact of diet and nutrition in the prevention and progression of hepatocellular carcinoma. Expert Rev. Gastroenterol. Hepatol. 2014, 8, 369-382. [CrossRef] [PubMed]

64. Darvesh, A.S.; Bishayee, A. Chemopreventive and therapeutic potential of tea polyphenols in hepatocellular cancer. Nutr. Cancer 2013, 65, 329-344. [CrossRef]

65. Yoysungnoen, P.; Wirachwong, P.; Changtam, C.; Suksamrarn, A.; Patumraj, S. Anti-cancer and anti-angiogenic effects of curcumin and tetrahydrocurcumin on implanted hepatocellular carcinoma in nude mice. World J. Gastroenterol. WJG 2008, 14, 2003. [CrossRef]

66. Cao, J.; Liu, Y.; Jia, L.; Zhou, H.-M.; Kong, Y.; Yang, G.; Jiang, L.-P.; Li, Q.-J.; Zhong, L.-F. Curcumin induces apoptosis through mitochondrial hyperpolarization and mtDNA damage in human hepatoma G2 cells. Free Radic. Biol. Med. 2007, 43, 968-975. [CrossRef] [PubMed]

67. Chuang, S.-E.; Kuo, M.; Hsu, C.; Chen, C.; Lin, J.; Lai, G.; Hsieh, C.; Cheng, A. Curcumin-containing diet inhibits diethylnitrosamine-induced murine hepatocarcinogenesis. Carcinogenesis 2000, 21, 331-335. [CrossRef] [PubMed]

68. Yeh, C.-B.; Hsieh, M.-J.; Lin, C.-W.; Chiou, H.-L.; Lin, P.-Y.; Chen, T.-Y.; Yang, S.-F. The antimetastatic effects of resveratrol on hepatocellular carcinoma through the downregulation of a metastasis-associated protease by SP-1 modulation. PLoS ONE 2013, 8, e56661. [CrossRef]

69. Martínez-Flórez, S.; Gutiérrez-Fernández, B.N.; Sánchez-Campos, S.; González-Gallego, J.; Tuñón, M.A.J. Quercetin attenuates nuclear factor- $\mathrm{KB}$ activation and nitric oxide production in interleukin-1 $\beta$-activated rat hepatocytes. J. Nutr. 2005, 135, 1359-1365. [CrossRef]

70. Waidmann, O. Recent developments with immunotherapy for hepatocellular carcinoma. Expert Opin. Biol. Ther. 2018, 18, 905-910. [CrossRef]

71. El-Khoueiry, A.B.; Sangro, B.; Yau, T.; Crocenzi, T.S.; Kudo, M.; Hsu, C.; Kim, T.-Y.; Choo, S.-P.; Trojan, J.; Welling, T.H., 3rd Nivolumab in patients with advanced hepatocellular carcinoma (CheckMate 040): An open-label, non-comparative, phase $1 / 2$ dose escalation and expansion trial. Lancet 2017, 389, 2492-2502. [CrossRef]

72. Crocenzi, T.S.; El-Khoueiry, A.B.; Yau, T.C.; Melero, I.; Sangro, B.; Kudo, M.; Hsu, C.; Trojan, J.; Kim, T.-Y.; Choo, S.-P.; et al. Nivolumab (nivo) in sorafenib (sor)-naive and -experienced pts with advanced hepatocellular carcinoma (HCC): CheckMate 040 study. J. Clin. Oncol. 2017, 35, 4013-4013. [CrossRef]

73. Yau, T.; Park, J.; Finn, R.; Cheng, A.-L.; Mathurin, P.; Edeline, J.; Kudo, M.; Han, K.-H.; Harding, J.; Merle, P. CheckMate 459: A randomized, multi-center phase III study of nivolumab (NIVO) vs sorafenib (SOR) as first-line (1L) treatment in patients (pts) with advanced hepatocellular carcinoma (aHCC). Ann. Oncol. 2019, 30, v874-v875. [CrossRef]

74. Zhu, A.X.; Finn, R.S.; Edeline, J.; Cattan, S.; Ogasawara, S.; Palmer, D.; Verslype, C.; Zagonel, V.; Fartoux, L.; Vogel, A. Pembrolizumab in patients with advanced hepatocellular carcinoma previously treated with sorafenib (KEYNOTE-224): A non-randomised, open-label phase 2 trial. Lancet Oncol. 2018, 19, 940-952. [CrossRef]

75. Merle, P.; Edeline, J.; Bouattour, M.; Cheng, A.-L.; Chan, S.L.; Yau, T.; Garrido, M.; Knox, J.J.; Daniele, B.; Zhu, A.X.; et al. Pembrolizumab (pembro) vs placebo (pbo) in patients (pts) with advanced hepatocellular carcinoma (aHCC) previously treated with sorafenib: Updated data from the randomized, phase III KEYNOTE-240 study. J. Clin. Oncol. 2021, 39, 268-268. [CrossRef]

76. Finn, R.S.; Ikeda, M.; Zhu, A.X.; Sung, M.W.; Baron, A.D.; Kudo, M.; Okusaka, T.; Kobayashi, M.; Kumada, H.; Kaneko, S. Phase Ib Study of Lenvatinib Plus Pembrolizumab in Patients With Unresectable Hepatocellular Carcinoma. J. Clin. Oncol. 2020. [CrossRef]

77. Pishvaian, M.J.; Lee, M.S.; Ryoo, B.Y.; Stein, S.; Lee, K.H.; Verret, W.; Spahn, J.; Shao, H.; Liu, B.; Iizuka, K.; et al. Updated safety and clinical activity results from a phase $\mathrm{Ib}$ study of atezolizumab + bevacizumab in hepatocellular carcinoma (HCC). Ann. Oncol. 2018, 29, viii718-viii719. [CrossRef]

78. Finn, R.S.; Qin, S.; Ikeda, M.; Galle, P.R.; Ducreux, M.; Kim, T.-Y.; Kudo, M.; Breder, V.; Merle, P.; Kaseb, A.O. Atezolizumab plus bevacizumab in unresectable hepatocellular carcinoma. N. Engl. J. Med. 2020, 382, 1894-1905. [CrossRef] [PubMed]

79. Yau, T.; Kang, Y.-K.; Kim, T.-Y.; El-Khoueiry, A.B.; Santoro, A.; Sangro, B.; Melero, I.; Kudo, M.; Hou, M.-M.; Matilla, A.; et al. Efficacy and Safety of Nivolumab Plus Ipilimumab in Patients With Advanced Hepatocellular Carcinoma Previously Treated With Sorafenib: The CheckMate 040 Randomized Clinical Trial. JAMA Oncol. 2020, 6, e204564-e204564. [CrossRef] 
80. Sivan, A.; Corrales, L.; Hubert, N.; Williams, J.B.; Aquino-Michaels, K.; Earley, Z.M.; Benyamin, F.W.; Lei, Y.M.; Jabri, B.; Alegre, M.-L. Commensal Bifidobacterium promotes antitumor immunity and facilitates anti-PD-L1 efficacy. Science 2015, 350, 1084-1089. [CrossRef]

81. Gopalakrishnan, V.; Spencer, C.N.; Nezi, L.; Reuben, A.; Andrews, M.; Karpinets, T.; Prieto, P.; Vicente, D.; Hoffman, K.; Wei, S. Gut microbiome modulates response to anti-PD-1 immunotherapy in melanoma patients. Science 2018, 359, 97-103. [CrossRef]

82. Matson, V.; Fessler, J.; Bao, R.; Chongsuwat, T.; Zha, Y.; Alegre, M.-L.; Luke, J.J.; Gajewski, T.F. The commensal microbiome is associated with anti-PD-1 efficacy in metastatic melanoma patients. Science 2018, 359, 104-108. [CrossRef]

83. Chaput, N.; Lepage, P.; Coutzac, C.; Soularue, E.; Le Roux, K.; Monot, C.; Boselli, L.; Routier, E.; Cassard, L.; Collins, M.; et al. Baseline gut microbiota predicts clinical response and colitis in metastatic melanoma patients treated with ipilimumab. Ann. Oncol. 2017, 28, 1368-1379. [CrossRef] [PubMed]

84. Routy, B.; Le Chatelier, E.; Derosa, L.; Duong, C.P.; Alou, M.T.; Daillère, R.; Fluckiger, A.; Messaoudene, M.; Rauber, C.; Roberti, M.P. Gut microbiome influences efficacy of PD-1-based immunotherapy against epithelial tumors. Science 2018, 359, 91-97. [CrossRef] [PubMed]

85. Pushalkar, S.; Hundeyin, M.; Daley, D.; Zambirinis, C.P.; Kurz, E.; Mishra, A.; Mohan, N.; Aykut, B.; Usyk, M.; Torres, L.E.; et al. The Pancreatic Cancer Microbiome Promotes Oncogenesis by Induction of Innate and Adaptive Immune Suppression. Cancer Discov. 2018, 8, 403-416. [CrossRef]

86. Ahmed, J.; Kumar, A.; Parikh, K.; Anwar, A.; Knoll, B.M.; Puccio, C.; Chun, H.; Fanucchi, M.; Lim, S.H. Use of broad-spectrum antibiotics impacts outcome in patients treated with immune checkpoint inhibitors. Oncoimmunology 2018, 7, e1507670. [CrossRef]

87. Sen, S.; Carmagnani Pestana, R.; Hess, K.; Viola, G.M.; Subbiah, V. Impact of antibiotic use on survival in patients with advanced cancers treated on immune checkpoint inhibitor phase I clinical trials. Ann. Oncol. 2018, 29, 2396-2398. [CrossRef]

88. Huemer, F.; Rinnerthaler, G.; Westphal, T.; Hackl, H.; Hutarew, G.; Gampenrieder, S.P.; Weiss, L.; Greil, R. Impact of antibiotic treatment on immune-checkpoint blockade efficacy in advanced non-squamous non-small cell lung cancer. Oncotarget 2018, 9 , 16512-16520. [CrossRef]

89. Baruch, E.N.; Youngster, I.; Ben-Betzalel, G.; Ortenberg, R.; Lahat, A.; Katz, L.; Adler, K.; Dick-Necula, D.; Raskin, S.; Bloch, N.; et al. Fecal microbiota transplant promotes response in immunotherapy-refractory melanoma patients. Science 2021, 371, 602-609. [CrossRef]

90. Dzutsev, A.; Badger, J.H.; Perez-Chanona, E.; Roy, S.; Salcedo, R.; Smith, C.K.; Trinchieri, G. Microbes and cancer. Annu. Rev. Immunol. 2017, 35, 199-228. [CrossRef]

91. Zheng, Y.; Wang, T.; Tu, X.; Huang, Y.; Zhang, H.; Tan, D.; Jiang, W.; Cai, S.; Zhao, P.; Song, R. Gut microbiome affects the response to anti-PD-1 immunotherapy in patients with hepatocellular carcinoma. J. Immunother. Cancer 2019, 7, 1-7. [CrossRef] [PubMed] 